\title{
Correction to: The value of procalcitonin for predicting urosepsis after mini-percutaneous nephrolithotomy or flexible ureteroscopy based on different organisms
}

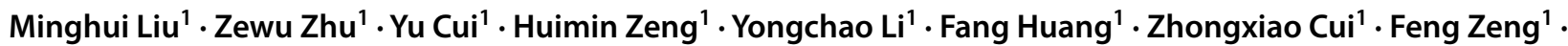
Zhiyong Chen ${ }^{1}$. Yang $\mathrm{Li}^{1} \cdot$ Xiaoqiong Zhang ${ }^{2}$. Jinbo Chen ${ }^{1} \cdot$ Hequn Chen ${ }^{1}$ (I)

Published online: 1 November 2021

(c) Springer-Verlag GmbH Germany, part of Springer Nature 2021

\section{Correction to: World Journal of Urology} https://doi.org/10.1007/s00345-021-03845-9

In the original publication of the article, the term "thrombus rate" in the last line of Fig. 2 was incorrect. The correct term should be "Urosepsis rate" and correct Fig. 2 is given below:

The original article has been corrected.
Publisher's Note Springer Nature remains neutral with regard to jurisdictional claims in published maps and institutional affiliations.

The original article can be found online at https://doi.org/10.1007/ s00345-021-03845-9.

Xiaoqiong Zhang

zhangxiaoqiong2021@126.com

$\triangle$ Jinbo Chen

chenjinbo1989@yahoo.com

$\triangle$ Hequn Chen

chenhequnxy@126.com

1 Department of Urology, Xiangya Hospital, Central South University, Changsha 410008, China

2 Transplantation Center, Xiangya Hospital, Central South University, Changsha 410008, China 
Fig. 2 Nomogram to predict the probability of post-PCNL and post-FURS urosepsis caused by GN bacteria

Points $\quad \begin{array}{lllllllllll}0 & 10 & 20 & 30 & 40 & 50 & 60 & 70 & 80 & 90 & 100\end{array}$

Postoperative PCT $>0.1 \mathrm{ng} / \mathrm{mL}$

0

Positive nitrite

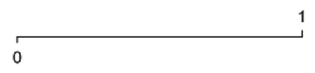

Operative time $>90 \mathrm{~min}$

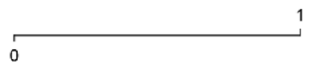

Total Points

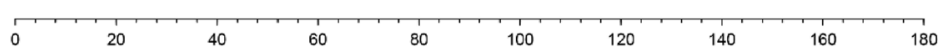

Urosepsis rate 